\title{
Claims of Effectiveness
}

Within the pro-homeschooling landscape there is quite a bit of promotion and fanfare surrounding claims that homeschooling, itself as a treatment, provides an environment that is more conducive to better academic outcomes and, as a result, produces better academic outcomes as compared to those of local public schools. For example,

Studies on the academic achievement of homeschoolers continue to demonstrate that they consistently score at or above average on standardized tests. In a 2009 study of standardized academic achievement tests (conducted by Brian Ray, PhD, with the NHERI), homeschooled children averaged at or above the eightieth percentile. The national average for traditionally schooled children on standardized tests is the fiftieth percentile. (Linsenbach, 2010, p. 28)

Similarly, the following is a filtered list of the "10o Reasons to Homeschool Your Kids" that relate to claims of effectiveness.

1. Homeschoolers perform well academically.

2. Whether early, late, or somewhere in the middle, homeschooling allows all children to move at their own pace.

3. You can choose from a panoply of curriculum options based on your children's needs and your family's educational philosophy.

4. Oryou can focus on unschooling, a self-directed education approach tied to a child's interests.

5. Homeschooling gives your kids plenty of time to play! In a culture where childhood free play is disappearing, preserving play is crucial to a child's health and well-being.

6. They can have more recess and less homework.

7. You can take advantage of weekly homeschool park days, field trips, classes, and other gatherings offered through a homeschooling group near you.

8. Homeschooling co-ops are growing, so you can find support and resources. 
9. Homeschooling learning centers are sprouting worldwide, prioritizing self-directed education and allowing more flexibility to more families who want to homeschool.

10. Parks, beaches, libraries, and museums are often less crowded during school hours, and many offer programming specifically for homeschoolers.

11. More urban parents are choosing to homeschool, prioritizing family and individualized learning.

12. Your kids' summertime can be fully self-directed, as can the rest of their year.

13. That's because kids thrive under self-directed education.

14. Your kids don't have to wait for adulthood to pursue their passions.

15. Self-directed learning centers for teen homeschoolers can provide a launchpad for community college classes and jobs while offering peer connection and adult mentoring.

16. You can preserve their natural childhood creativity.

17. Schools kill creativity, as Sir Ken Robinson proclaims in his TED Talk, the most-watched one ever.

18. Homeschooling might even help your kids use their creativity in remarkable ways, as other well-known homeschoolers have done.

19. With homeschooling, learning happens all the time, all year round. There are no arbitrary starts and stops.

20. You can take vacations at any time of the year without needing permission from the principal.

21. Or you can go world-schooling, spending extended periods of time traveling the world together as a family or letting your teens travel the world without you.

22. Technological innovations make self-education through homeschooling not only possible but also preferable.

23. Free, online learning programs like Khan Academy, Duolingo, Scratch, Prodigy Math, and MIT OpenCourseWare complement learning in an array of topics, while others, like Lynda.com and Mango, may be available for free through your local public library.

24. Teen homeschoolers can enroll in an online high school program to earn a high school diploma if they choose.

25. But young people don't need a high school diploma in order to go to college.

26. Many teen homeschoolers take community college classes and transfer into four-year universities with significant credits and cost-savings. 
Research suggests that community college transfers also do better than their non-transfer peers.

27. Homeschooling may be the new path to Harvard.

28. Many colleges openly recruit and welcome homeschoolers because they tend to be "innovative thinkers."

29. Hybrid homeschooling models are popping up everywhere, allowing more families access to this educational option.

30. Homeschooling grants children remarkable freedom and autonomy, particularly self-directed approaches like unschooling, but it's definitely not the Lord of the Flies.

31. Homeschooling allows for much more authentic, purposeful learning tied to interests and everyday interactions in the community rather than contrived assignments at school.

32. Homeschooling can be preferable to school because it's a totally different learning environment. As homeschooling pioneer John Holt wrote in Teach Your Own: "What is most important and valuable about the home as a base for children's growth in the world is not that it is a better school than the schools but that it isn't a school at all."

33. Immersed in their larger community and engaged in genuine, multi-generational activities, homeschoolers tend to be better socialized than their schooled peers. Newer studies suggest the same.

34. Homeschoolers interact daily with an assortment of people in their community in pursuit of common interests, not in an age-segregated classroom with a handful of teachers.

35. They can dig deeper into emerging passions, becoming highly proficient.

36. They also have the freedom to quit.

37. They can spend abundant time outside and in nature. (Adapted from McDonald, 2019)

Of the myriad of rationales and justifications for homeschooling, the claim of effectiveness is among the most cited reason. The majority of the claims about effectiveness are largely overstated. That is, while homeschooled students do, on average, perform at or above the academic levels of their traditional public school counterparts, there is little evidence that homeschooling - as a treatment - is responsible for the outcomes as other factors such as family socioeconomic status likely play a larger determining factor. As such, students who are homeschooled and enter/exit traditional public schools tend to maintain 
their higher level of academic achievement suggesting greater causality of other out-of-school factors rather than the treatment itself.

On the face of it these claims are accurate but are exceedingly problematic for a number of reasons. Namely among those reasons are the comparison groups themselves as it is an apples to oranges comparison when the full context is understood.

Comparing student academic outcomes has long been a quest within the commodified and quantified era of accountability. Moreover, the comparison of a student's performance to their peer's performance is in alignment with our broad societal commitment to the myth of meritocracy where such comparisons are required to determine the worth and value of a human within our capitalistic economy. As education is understood, widely, as a level playing field despite the myriad reasons it should not be understood as one, the relative difference or variance between student academic performance purports to tell us something about the student and the quality of the school in which she attends. Following the logic, as it were, is that a singular student who does well relative to her peers is the result of hard work. The collective average of student academic performance at School A relative to the performance of the average student performance of students at School B purport to tell us about the relative difference in overall quality of the schools. If, say, the average SAT score of students at School B is $20 \%$ higher than the average score of students at School A, then conclusions are often drawn about School B "producing" better students or providing better educational experiences that lead to such outcomes while School A is understood to be "failing" or lacking in some way. Within the broader push to privatize and monetize schools, reformers would call for School A to be converted into a charter school, converted into a "turnaround" school, provide students with vouchers to attend private schools, or transfer to School B. All of these proposed options would result in fewer funds for School A, an exodus of students who come from families with the financial means to enact school choice decisions, thus leaving School A with a higher concentration of lower-performing students from less affluent families, thus driving scores down and becoming further proof of the "failure" and need to privatize in some way. And, yet, comparing a singular student in either School A or B with another student in the same school, or the other, is fraught with problems. Decades of research have concluded, definitively, that out-of-school factors inform two-thirds of all variance between student academic outcomes (Berliner, 2006, 2013; Berliner \& Biddle, 1995; Berliner \& Glass, 2014; Bowles \& Gintis, 1976; Brewer \& Myers, 2015; Carter \& Welner, 2013; Coleman, 1990; Coleman et al., 1966; Ennis, 1976; Jencks \& Phillips, 1998; Jencks et al., 1972; Ladson-Billings, 2006; Rothstein, 2004; Wilkinson \& Pickett, 2010) . One-third of 
the variance can be explained by in-school factors. With this understanding, it becomes clearer that comparing the academic performance of students even within the same school is not as clear-cut as reformers would have us believe as the vast majority of the variance is not explained by the school itself and, thus, conclusions and policy prescriptions that rely on assuming that it is the school - as a treatment - are misguided.

With that in mind, comparisons of the academic outcomes of students who are homeschooled to those who attend public schools is ever more problematic. Comparing the average SAT scores (Linsenbach, 2010), grades, test scores, graduation rate, and college acceptance/competition rates of homeschooled students with the average of public school students requires ignoring the glaring contextual differences between the typical homeschooled student and the typical student attending public schools. As will be explicated in greater detail in the following chapter, the median household income for American families in 2019 was approximately $\$ 63$, ooo while the median household income for families that homeschooled during the same year was approximately $\$ 94,000$. The role that a family's socioeconomic status has on informing student academic outcomes has been fully documented over a nearly seventy year period of time.

A student's socioeconomic (SES) status is historically the most prominently considered factor (though, as will be explicated below, the sEs factor is closely related to racial factors in U.S. history). Family SES is the leading factor when predicting all forms of social and economic inequality in the U.S. - including educational opportunity and educational outcomes.

Evidence suggests that "the influence of social class characteristics is probably so powerful that schools cannot overcome it, no matter how well trained are their teachers and no matter how well designed are their instructional programs and climates" (Rothstein, 2004, p. 5). Further, "the spatial concentration of affluence and poverty in rich and poor school districts raises the odds that affluent children will receive a superior education and that poor children will get inferior schooling, virtually guaranteeing the intergenerational transmission of class position" (Massey, 2007, p. 197). Rothstein further points out that children from lower SES deciles are exposed to "more lead poisoning, more asthma, poorer nutrition, less adequate pediatric care, more exposure to smoke, and a host of other problems" (Rothstein, 2004, p. 3) when compared to students from higher ses deciles. Indeed, when measuring student educational outcomes, it becomes clear that the leading factor in determining and predicting educational outcomes rests almost singularly with a student's SES. That is, regardless of where students score on early tests, SEs factors have such a powerful influence on results that, over time, higher scoring students from low SES families are surpassed by their initially lower scoring but higher SES 
peers. With connections to the argument set forth by Bowles and Gintis (1976), Paul Willis' work reinforces the evidence that a schools' function is to reproduce class stratification - in the case of Willis' young men who reproduced their class by way of opposition of the cultures of the ruling elite, the provision of an equal education for them would have caused menial labor employers to "strugg[le] to press [the boys] into meaningless work" (Willis, 1977, p. 177). That is, work that is associated with low wages and the working class.

Because we know from decades of research that a family's socioeconomic status is the key indicator of informing academic outcomes, it should be of little surprise that homeschooled students generally do better than their public school counterparts. This is not a result of the homeschooling itself, it is simply a result of coming from more money. Comparatively, private schools generally outperform public schools on the NAEP each year. However, when controlling for economic factors by comparing the scores of similarly wealthy families who attend public schools, the students in the public schools far outperform their private school counterparts who share similar home economic realities (Lubienski \& Lubienski, 2014).

Reports of academic outcomes at a local public school entail a myriad of factors that provide both an overarching snapshot of the academic environment but also numerous snapshots and disaggregated data between a plethora of testing and the type(s) of students taking those assessments. I do, up front, want to be clear that I am not taking a position of support for the status quo of the assessment practices and hyper-accountability culture within traditional public schools. There is much to be explored and said about how these environments can be negative to both the culture of education and, in some cases, individual students or student groups and such conversations are wholly worthwhile (see, for example, Ahlquist, 2011; Baker, 2011; Berliner, 2006, 2013; Darling-Hammond, 2012; Glass, 2008; Goldstein, 2014; Haertel, 2013; Hursh, 2011; Jencks \& Phillips, 1998; Kumashiro, 2015; Labaree, 2012; Lack, 2011; Mathis, 2013; Newman \& Chin, 2003; Olsen, 2015; Peterson et al., 2011; Ravitch, 2010; Willis \& Sandholtz, 2009). That said, what I am interested in here is a discussion of the fallacies of comparing the academic outcomes of students who are homeschooled to those of students in public schools.

There are a variety of ways to measure academic achievement or academic outcomes. In normal usage, discussions surrounding achievement typically refer to student test scores and/or student GPAs in some cases (which are derived from a student's overall scores within and across their course-specific assessments). Academic outcomes, on the other hand, often refer to student graduation rates, drop-out rates, college acceptance rates, college matriculation rates, and college completion rates. In some ways, what is measured as an outcome can be thought of in terms of what the tangible outcomes of 
schooling and education can, or should, produce. Academic achievement again, not without some important caveats that should be considered - is more a measurement of the transactional events within the schooling and education process and often a singular glimpse - or gauge of temperature by way of a metaphor - of a particular moment in time. While some of these achievement metrics are somewhat cumulative in nature (think, for example, a high school graduation test that purports to assess the content knowledge learned over the course of four years of study), as a function of the limitations of testing, they still provide a singular glimpse into what we might call learning. That is, the test scores of a student taking a high school graduation test may very well be influenced by external factors such as sleep, hunger, student volition during the day of the exam, temperature in the room, etc., and should be understood within such possible limitations.

One of the largest claims of homeschooling effectiveness relative to public schools is its ability to provide individualized learning or "personalized learning" in ways that are not, apparently, possible in group settings. There, again, are some issues here with the delivery method and the person delivering the treatment. While more individualized learning approaches have benefits (also noting that this can be, and is done, in public K-12 schools) this approach as a treatment, alone, may not be sufficient nor appropriate depending on how it is delivered and who is doing the delivery. To return to a medical analogy, an individualized plan of surgery and subsequent individualized course of antibiotics and medicines that take the individual's heath history and contemporary medical concerns into consideration and individualized physical therapy are, with little doubt, the best way to approach most medical procedures. That is, individualized to the patient's needs and speed of recovery. However, while this process is ideally individualized, if the individual overseeing the surgery, administration of medicine, and facilitating the physical therapy is not a licensed and trained medical professional, then the best individualized healthcare plan is worthless. Moreover, the increased access to a myriad of technology and YouTube videos, would not make such an individual more suited to provide such medical intervention. Despite all of this, many homeschooling families claim that parents are the best suited facilitator of this individualized approach to learning despite having any training, credentialing, or licensure at providing such pedagogical experiences. In fact, it is entirely feasible that the advent on-demand echo chamber inducing technologies may prove to negatively reinforce many of these approaches (Bryant, 2020). In our over-the-top societal praise of billionaires and tech-gurus, Business Insider has even pushed homeschooling as an ideal educational delivery method because "Bill Gates and Mark Zuckerberg are big fans of personalized learning, since it tends to use technology as a way to tailor lesson plans to students" (Weller, 2018). Nowhere 
in the article was it pointed out that two tech industry giants who rely on the sales and use of technology to bolster their fortunes would, of course, be in favor of expanding the reach of technology.

Returning to the problem at hand of comparing the academic achievements and academic outcomes of homeschooled students to those of students in public schools is, again, presents a problem in comparison groups. All of the factors explicated above in terms of academic achievement and academic outcomes reported by a local public school or school district are reported as averages or medians of hundreds, if not thousands, of students. Thus, on its face, comparing the academic achievements and outcomes of, say, a singular homeschooled student to the average or median of thousands of public school students is statistical malfeasance. While individual students (in both homeschooling and public schooling environments) can compare their individual scores and outcomes to the larger group median or average, few concluding generalizations can, or should, be drawn about the comparative experiences.

Another problematic function of the comparison of a small group of homeschooled students to those of the millions of public school students is that because public schools operate within, and under, the oversight of local, state, and federal accountability, all student metrics associated with achievement and outcomes are reported. As Bartholet (2019) points out, because not all homeschooled students are required to even notify the State about their decision to homeschool, it raises significant questions about comparing the self-reported metrics from homeschooled students to all public school students. That is,

Studies which make claims about homeschoolers' performance capture only those who are most visible because they emerge from isolation to do things like take standardized tests, apply to college, or attend college. If, as is often the case, parents are in charge of test administration, they may only submit test results or reveal them to researchers if they are positive, either for friar of state intervention, or because researchers are often only looking for positive results. This means studies generally focus on a small subset of the most successful homeschoolers, and miss out entirely on the most at-risk [or lower performing] subsets. (Bartholet, 2019, p. 16)

And, as was noted previously, what we "know" about homeschooling families tends to be limited as their participation in Department of Education surveys is the lowest participation rate of all groups surveyed.

While the effects of poverty and lower SES can create similar barriers to equal educational opportunities and outcomes for those who experience such factors, racial inequality often exacerbates those effects of sEs. Namely, race is a dominant factor alone but is often correlated with SES factors in the US given 
the nation's abhorrent history of racial relations between Whites and nonWhites. That is, a Black student, for example, is far more likely to experience poverty in the US than a White student and subsequently attend a school that receives less financing than a predominately White school (Jencks et al., 1972). As a result, while racial factors are important considerations, they can become magnified through the experience of economic inequality. For example, "in recent decades, [B]lacks have experienced substantially less upward intergenerational mobility and substantially more downward intergenerational mobility than [W]hites" (Mazumder, 2014, p. 2). Pauline Lipman contends, that the "correlation between poverty and low-academic performance, school completion, and other education indicators [is] well-documented, as is the relationship between race/ethnicity and educational outcomes" (Lipman, 2011, p. 79), even within efforts to improve opportunity based on "mixed-income" schooling, the actual "subtext is race" (Lipman, 2011, p. 75).

So, what does all of this mean for comparisons of academic outcomes between homeschooled students and those who attend public schools? While children who are homeschooled often outperform their public school counterparts the difference, simply put, can be attributed to the massive disparity in family income and what that income can, and does, mean for educational opportunities, educative experiences, access to technology, books, trips, etc. and to a great extent, an overall lack of detailed and transparent reporting from families who homeschool.

\section{References}

Ahlquist, R. (2011). The 'empire' strikes back via a neoliberal agenda: Confronting the legacies of colonialism. In R. Ahlquist, P. C. Gorski, \& T. Montano (Eds.), Assault on kids: How hyper-accountability, corporatization, deficit ideologies, and Ruby Payne are destroying our schools (pp. 9-32). Peter Lang Publishing.

Baker, K. (2011, Spring). High test scores: The wrong road to national economic success. Kappa Delta Pi Record, 47, 116-120.

Bartholet, E. (2019). Homeschooling: Parent rights absolutism vs child rights to education \& protection. Arizona Law Review, 62(1), 1-80.

Berliner, D. C. (2006). Our impoverished view of educational reform. Teachers College Record, 108, 949-995.

Berliner, D. C. (2013). Effects of inequality and poverty vs. Teachers and schooling on America's youth. Teachers College Record, 115, 1-26.

Berliner, D. C., \& Biddle, B. J. (1995). The manufactured crisis: Myths, fraud, and the attack on America's public schools. Addison-Wesley. 
Berliner, D. C., \& Glass, G. V. (2014). 50 myths and lies that threaten America's public schools: The real crisis in education. Teachers College Press.

Bowles, S., \& Gintis, H. (1976). Schooling in capitalist America. Harper Collins.

Brewer, T. J., \& Myers, P. S. (2015). How neoliberalism subverts equality and perpetuates poverty in our nation's schools. In S. N. Haymes, M. V. d. Haymes, \& R. Miller (Eds.), The routledge handbook of poverty in the United States (pp. 190-198). Routledge.

Bryant, J. (2020). Homeschooling movement sees opportunity during health calamity. Retrieved April 7, 2020, from https://www.laprogressive.com/homeschoolingmovement/

Carter, P. L., \& Welner, K. G. (Eds.). (2013). Closing the opportunity gap: What America must do to give every child and even chance. Oxford University Press.

Coleman, J. (1990). Equality and achievement in education. Westview Press.

Coleman, J., Campbell, E. Q., Hobson, C. J., McPartland, J., Mood, A. M., Weinfeld, F. D., \& York, R. L. (1966). Equality of educational opportunity. U.S. Department of Health, Education, and Welfare.

Darling-Hammond, L. (2012). Value-added teacher evaluation: The harm behind the hype. Education Week, 37(24), 32-24.

Ennis, R. H. (1976). Equality of educational opportunity. Educational Theory, 26(1), 3-18.

Glass, G. V. (2008). Fertilizers, pills, and magnet strips: The fate of public education in America. Information Age Publishing.

Goldstein, D. (2014). The teacher wars: A history of America's most embattled profession. Doubleday.

Haertel, E. H. (2013). Reliability and validity of inferences about teachers based on student test scores. ETS. https://www.ets.org/Media/Research/pdf/PICANG14.pdf

Hursh, D. (2011). The Gates Foundation's interventions into education, health, and food policies: Technology, power, and the privatization of political problems. In P. E. Kovacs (Ed.), The Gates foundation and the future of U.S. "public" schools (pp. 39-52). Routledge.

Jencks, C., \& Phillips, M. (Eds.). (1998). The Black-White test score gap. Brookings Institution Press.

Jencks, C., Smith, M., Acland, H., Bane, M. J., Cohen, D., Gintis, H., ... Michelson, S. (1972). Inequality: A reassessment of the effect of family and schooling in America. Basic Books, Inc.

Kumashiro, K. (2015). Review of proposed 2015 federal teacher preparation regulations. National Education Policy Center. http://nepc.colorado.edu/thinktank/reviewproposed-teacher-preparation

Labaree, D. (2012). The lure of statistics for educational researchers. In P. Smeyers \& M. Depaepe (Eds.), Educational research: The ethics and aesthetics of statistics (pp. 13-25). Springer.

Lack, B. (2011). Anti-democratic militaristic education: An overview and critical analysis of KIPP schools. In R. Ahlquist, P. C. Gorski, \& T. Montano (Eds.), Assault on 
kids: How hyper-accountability, corporatization, deficit ideologies, and Ruby Payne are destroying our schools (pp. 65-90). Peter Lang Publishing.

Ladson-Billings, G. (2006). From the achievement gap to the education debt: Understanding achievement in U.S. schools. Educational Researcher, 35(7), 3-12.

Linsenbach, S. (2010). The everything guide to homeschooling: All you need too create the best curriculum and learning environment for your child. Adams Media.

Lipman, P. (2011). The new political economy of urban education: Neoliberalism, race, and the right to the city. Routledge.

Lubienski, C., \& Lubienski, S. (2014). The public school advantage: Why public schools outperform private schools. The University of Chicago Press.

Massey, D. S. (2007). Categorically unequal: The American stratification system. Russell Sage Foundation.

Mathis, W. (2013). Research-based options for education policymaking. National Education Policy Center. http://nepc.colorado.edu/publication/options

Mazumder, B. (2014). Black-White differences in intergenerational economic mobility in the United States. Federal Reserve Bank of Chicago.

McDonald, K. (2019). 100 reasons to homeschool your kids. Retrieved July 8, 2019, from https://fee.org/articles/10o-reasons-to-homeschool-your-kids/

Newman, K. S., \& Chin, M. M. (2003). High stakes: Time poverty, testing, and the children of the working poor. Qualitative Sociology, 26(1), 3-34.

Olsen, R. (2015). The toxic myth of good and bad teachers. Retrieved January 16, 2017, from https://www.richardolsen.me/b/2015/05/the-toxic-myth-of-good-and-badteachers/

Peterson, E. R., Rubie-Davies, C. M., Elley-Brown, M. J., Widdowson, D. A., Dixon, R. S., \& Irving, S. E. (2011). Who is to blame? Students, teachers and parents views on who is responsible for student achievement. Research in Education, 86(1), 1-12.

Ravitch, D. (2010). The death and life of the great American school system: How testing and choice are undermining education. Basic Books.

Rothstein, R. (2004). Class and schools: Using social, economic, and educational reform to close the Black-White achievement gap. Economic Policy Institute.

Weller, C. (2018). Homeschooling could be the smartest way to teach kids in the 21st century - Here are 5 reasons why. Retrieved April 1, 2020, from https://www.businessinsider.com/reasons-homeschooling-is-the-smartest-way-toteach-kids-today-2018-1

Wilkinson, R., \& Pickett, K. (2010). The spirit level: Why greater equality makes societies stronger. Bloomsbury Press.

Willis, J., \& Sandholtz, J. (2009). Constrained professionalism: Dilemmas of teaching in the face of test-based accountability. Teachers College Record, 111(4), 1065-1114.

Willis, P. (1977). Learning to labor: How working class kids get working class jobs. Columbia University Press. 